\title{
Reuna
}

\section{Desenvolvimento sustentável em turismo: um estudo para a capacitação de gestores com ensino a distância}

http://dx.doi.org/10.21714/2179-8834/2018v23n4p42-61

\author{
Hamilton Pozo \\ Lara, Brasil. \\ E-mail: hprbrazil@hotmail.com \\ Elio Takeshy Tachizawa \\ Faculdade de Campo Limpo Paulista (FACCAMP), Brasil. \\ E-mail: usptakes@uol.com.br
}

Centro Estadual de Educação Tecnológica Paula Souza (CEETEPS) / Fatec Baixada Santista Rubens

Submissão: 20 Ago. 2017 Publicação: 30 Mai. 2019. Sistema de avaliação: Double blind review. Centro Universitário UNA, Belo Horizonte - MG, Brasil. Editor geral: Prof. Dr. Gustavo Quiroga Souki

Este artigo encontra-se disponível nos seguintes endereços eletrônicos:

http://revistas.una.br/index.php/reuna/article/view/971

http://dx.doi.org/10.21714/2179-8834/2018v23n4p42-61

\section{Resumo}

Esta pesquisa aborda a implementação de um programa de treinamento virtual, que serviu de suporte a um programa integrado de Turismo sustentável, para capacitação de gestores no contexto de um consórcio de prefeituras municipais. Para tanto, adotou-se como metodologia o enfoque de estudo de caso. O objeto do estudo foi a Prefeitura de Campo Limpo Paulista, situada no sudoeste do estado de São Paulo, que liderou o programa de treinamento junto a outras prefeituras das cidades circunvizinhas. As prefeituras dessas cidades vivenciavam um processo de mudança em direção a um modelo de desenvolvimento regional, apoiado no Turismo sustentável. A relevância deste estudo é enfatizada pela obtenção de uma efetiva capacitação em Turismo dos gestores das prefeituras associadas a esse consórcio regional, a fim de habilitá-los para gerenciar sua cadeia turística integrada aos processos sistêmicos de apoio, dentro dos contornos de uma filosofia de desenvolvimento regional articulado.

Palavras-chave: Turismo. Hospitalidade. Desenvolvimento sustentável. Treinamento virtual. 


\section{ABSTRACT}

This research addresses the implementation of a virtual training program that supported an integrated sustainable tourism program to train managers in the context of a consortium of municipal governments. Therefore, the case study approach was adopted as a methodology. The object of this study was the City of Campo Limpo Paulista, located in the southwest of the state of São Paulo, Brazil, which led the training program with other city halls in the surrounding cities. The prefectures of these cities experienced a process of change towards a model of regional development, supported by sustainable tourism. The relevance of this study is emphasized by obtaining an effective training in Tourism of the managers of the municipalities associated with this regional consortium, in order to enable them to manage their tourism chain integrated to the systemic processes of support, within the contours of a development philosophy regional cooperation.

Keywords: Tourism. Hospitality. Sustainable development. Virtual training.

\section{Introduction}

A conexão do mundo globalizado possibilitou as inovações, aumentando a capacidade de comunicação e de processamento da informação, o que promoveu a criação de novos produtos, processos e tecnologias e dentre eles, a Internet. Com a socialização da informação e do conhecimento, por meio da sociedade em rede, surgiu uma nova forma de interação entre as instituições e seus indivíduos. Nesse novo cenário surgiram os ambientes virtuais de aprendizagem que permitiram a gestão de cursos a distância, proporcionando recursos necessários aos educadores para a operacionalização de programas de ensino com identidade e objetivo claramente definidos no processo do ensino-aprendizagem. Para atender a esta emergente demanda, foram desenvolvidos softwares livres, disseminados de forma a não reter o conhecimento acumulado sob patentes (STALLMAN, 2010, p.19).

$E$, para que um software seja "free", certos requisitos foram estabelecidos, segundo a Free Software Foundation (2009, p.47), tais como: executar o programa para qualquer propósito em termos de liberdade; analisar e adaptá-lo para, as suas necessidades; redistribuir cópias; aperfeiçoar o programa e disseminar seus aprimoramentos.

Esse novo contexto tecnológico trouxe o conceito de software livre, entre eles - Moodle, que é abordado no presente trabalho, a fim de promover a capacitação de gestores em Turismo.

A aplicação desse software livre deu-se junto à Prefeitura de Campo Limpo Paulista, que, na época, liderava um processo de desenvolvimento regional, junto a outras prefeituras das cidades circunvizinhas. Vivia-se em uma significativa transformação das prioridades de desenvolvimento regional, baseando-se na premissa de que a união de governos municipais seria capaz de provocar uma sinergia de ações, visando os objetivos maiores da região com essa abordagem de consórcio de municípios. Para este desenvolvimento leva em conta os aspectos locais relativo à especificidade regional (ANSARAH, 2009). 
No contexto atual, entende-se que o desenvolvimento regional não está unicamente relacionado ao crescimento econômico, mas também à melhoria da qualidade de vida das pessoas e à conservação do meio ambiente: três fatores que estão interrelacionados e interdependentes. $O$ aspecto econômico implica aumento da renda e riqueza, além de condições dignas de trabalho. Do mesmo modo, segundo Ansarah (2009), a problemática ambiental não pode ser dissociada da social. O desenvolvimento local pressupõe uma transformação consciente da realidade local e isso implica uma preocupação, não apenas com a geração atual, mas também com as gerações futuras e é neste aspecto que o fator ambiental assume fundamental importância.

O desgaste ambiental pode não interferir diretamente nessa geração, mas pode vir a comprometer as próximas gerações (SACHS, 2007). Neste cenário, 0 Governo Municipal de Campo Limpo Paulista, priorizou o Turismo sustentável como meio de promover seu desenvolvimento local, em conjunto com os governos municipais de suas cidades circunvizinhas, para que assim, como um todo, formassem uma região única, que representasse um potencial turístico maior do que a mera soma individual das potencialidades individuais de cada município.

O Turismo, de fato, vem exercendo um papel decisivo em vários países, sendo, em muitos casos (BISSOLI, 2001), o verdadeiro carro-chefe do desenvolvimento econômico, social e cultural. O Brasil vem, neste contexto, progressivamente, proporcionando especial prioridade econômica ao desenvolvimento turístico de diversas regiões do país. O potencial que a Nação e, particularmente, Campo Limpo Paulista e Região possuem é muito expressivo: riquezas naturais; acervo cultural e artístico; cadeia de frutas; circuito de pousadas e hotéis; patrimônio histórico, folclórico e gastronômico; além disso, uma população bastante receptiva e calorosa, o que se torna um diferencial turístico.

\section{Fundamentação Teórica}

\subsection{Ambiente virtual}

As tecnologias da informação no cenário da Economia capitalista, iniciada na Inglaterra durante a Revolução Industrial, passaram por transformações em cinco revoluções tecnológicas. E, portanto, cada uma dessas destruições criadoras schumpeterianas, conforme termo cunhado por Shibayama (2018) provocam mudanças em direção a novos insumos, produtos e segmentos industriais. Essa abertura de novas possibilidades no cenário da sociedade da informação refere-se ao atual estágio de desenvolvimento como economia do aprendizado (SCHUMPETER, 2017).

Desse contexto, emerge o conceito do virtual e da cibercultura, que segundo Caram, e Bizelli (2016) é o conjunto de técnicas (materiais e intelectuais), de práticas, de atitudes, de modos de pensamento e de valores que se desenvolvem juntamente com o crescimento do ciberespaço. É o espaço físico dando lugar ao espaço virtual, como o ambiente Moodle, que favorece a Educação a distância, como uma inovadora modalidade de treinamento e de desenvolvimento organizacional.

De fato, a importância do aprendizado em todos os campos do saber, inclusive no Turismo, está relacionada à sua conexão com essa inovação. 
Gregersen e Johnson (2008, p.73) definem inovação como a introdução de um novo conhecimento na Economia ou como novas combinações entre antigos conhecimentos. $\mathrm{Na}$ economia do conhecimento, o software é um componente vital para o aprendizado. Atualmente, é o software que institui as regras fundamentais para o processamento da informação e, desta forma, para toda a Economia e Sociedade (BARMA, DURBIN, LORBER e WHITLARK, 2016).

Por outro lado, o software é também um grande limitador da difusão da tecnologia. A estória de patentes de software é recente, vem desde a década de 1980 e sempre gerou controvérsias. De acordo com Bria, (2017), esse modelo de negócios, baseado em software proprietário, tem sido repensado.

Algumas iniciativas inovadoras nesta área adotaram um novo modelo de desenvolvimento e de distribuição de programas aplicativos, na forma de software livre. O código fonte é aberto e fica disponível para todos e as licenças de uso são, na maioria das vezes, gratuitas, utilizando um conceito de propriedade intelectual contrário ao copyright, e denominado copyleft (STALLMAN, 2008, p.71). De acordo com Song, Li, and Cao (2017), o Governo pode exercer pressão, na forma de pretender ser o indutor da transição tecnológica. Soma-se a isso o fato de a tecnologia não ser neutra, conforme apresenta Lovatel (2016), e qualquer decisão tomada, principalmente, na área das tecnologias da informação, poderá provocar impactos em toda a sociedade.

Segundo Harte et al. (2017), se o mercado tornar-se dominante, e se começar a dirigir até mesmo os serviços do governo ou os meios pelos quais tais serviços são oferecidos, poderá se tornar inviável financeiramente, caso o governo pretenda vir a satisfazer as necessidades de todos os cidadãos. Consoante Lovatel (2016), em relação ao Estado, as experiências têm apontado para a importância de se articular as decisões para não dispersar recursos escassos, e nesse caso, torna-se necessário o envolvimento democrático das várias esferas de governo.

No Brasil, os direitos sobre software estão regularizados pela Lei de Direitos Autorais ( $n^{\circ}$ 9.610, de 29/02/98) e pela Lei do Software ( $\mathrm{n}^{\circ}$ 9.609, de 19/02/98). Essa proteção à propriedade intelectual independe de registro e, portanto, um software como o Moodle, nos contornos delineados na presente proposta de capacitação gerencial em Turismo, não necessita de nenhuma formalização para que a sua tecnologia esteja automaticamente protegida.

\subsection{Turismo e hospitalidade}

Para o Instituto Brasileiro de Turismo (EMBRATUR, 2018), o turismo é gerado pelo deslocamento temporário e voluntário de pessoas para fora dos limites da região em que têm residência fixa, por um motivo qualquer, desde que não seja para desenvolver atividade remunerada no local a ser visitado.

Para Gössling e Lane, (2014) o setor de turismo pode ser bastante beneficiado com o uso da Internet, pois existe um potencial para diminuir consideravelmente seus custos de transação. Além disso, a internet traz uma série de oportunidades de negócios e de desafios para as empresas que atuam na indústria do turismo, principalmente para aquelas que pretendem atuar em um segmento de mercado e realizar a distribuição dos seus produtos. 
O turismo é um fenômeno social, econômico e cultural que envolve pessoas. É um ramo das Ciências Sociais e não apenas das Ciências Econômicas, apesar de esta última ser a possível razão de tal movimento, o turismo transcende as esferas das meras relações da balança comercial. A importância crescente da categoria de estilo de vida emergiu depois de a indústria hoteleira passar a enxergar a necessidade de padronização das instalações e, assim promover o surgimento de novos clientes. Pode-se argumentar ainda que os hotéis historicamente têm sido um local diferenciado e as marcas globais de hotéis trouxeram um novo paradigma, estilos e conforto (DAVID, JONES, DAY e QUADRI-FELITTI (2013).

O Turismo é a atividade do setor terciário que mais cresce no Brasil e no mundo, movimentando, direta ou indiretamente mais de U\$ 6 trilhões (EMBRATUR, 2018). É um ramo de fundamental importância para o profissionalismo do setor e necessário para a economia do Brasil, que possui um excelente potencial turístico. Os conceitos de variedade relacionada e não relacionada representam perspectivas novas e promissoras para entender e analisar o desenvolvimento do destino turístico. No entanto, de máxima importância é a chamada para a pesquisa que pode testar rigorosamente cada problema. Categoria de destino ou estrutura de propriedade de destino (AARSTAD, KVITASTEIN e JAKOBSEN, 2016)

Fernandes, Altura e Laureano (2018) definem hospitalidade como o ato de acolher e de prestar serviços a alguém, que por algum motivo esteja fora do seu local de domicílio. A hospitalidade não consiste apenas em dar um espaço ao outro, mas em receber o outro no seu espaço. Lashley; Morrison (2004, p.21) melhor expressa a definição anterior, como: o entendimento mais amplo a respeito da hospitalidade sugere, em primeiro lugar, que esta é fundamental ao relacionamento construído entre anfitrião e o hóspede. Para Lashley; Morrison (2004) a hospitalidade constitui-se em um meio de criar ou consolidar relacionamentos com estranhos, pelo qual a sociedade muda, cresce, se renova e se reproduz dentro do domínio social, privado e comercial.

De acordo com Selwin, (2004, p.26) a hospitalidade é um conjunto de comportamentos originários da própria base da sociedade, cuja função principal é estabelecer relacionamentos ou fortalecer os relacionamentos já existentes. Nesse sentido, Camargo (2015) traz que a hospitalidade é o ato humano (...) de recepcionar, hospedar, alimentar e entreter pessoas temporariamente deslocadas de seu habitat.

Como mostra os estudos de Fernandes, Altura e Laureano (2018), a hospitalidade não consiste apenas em receber o outro, visto que o ato de hospedar e de ser hospitaleiro é muito mais complexo que simplesmente receber o visitante, pois consiste na união, ou melhor, na aproximação de culturas, costumes e pessoas diferentes, sendo uma relação de troca de valores entre o visitado e visitante. Em suma, a hospitalidade pode ser compreendida por diversas formas e por inúmeros fatores e com distintos conceitos e associações, tais como: confortabilidade, receptividade, sociabilidade, alimentação, lazer entre outras e não tendo uma forma e conceito único e universal. Portanto para Fernandes, Altura e Laureano (2018), a hospitalidade constitui-se em um meio de criar ou consolidar relacionamentos com estranhos, pelo qual a sociedade muda, cresce, se renova e se reproduz dentro dos domínios social, privado e comercial. 
No entanto, para Ukpabi e Karjaluoto, (2017) a hospitalidade consiste em ultrapassar uma fronteira sem aboli-la, considerando-a como uma permissão temporária. É o primeiro grau de compromisso, sendo uma despesa que permite dilatar ou se contrair, multiplicando as relações no seu interior ou interagir na direção de outros grupos (LOPES e OLIVEIRA, 2013). Aquele que recebe dá alimento, espaço, proteção e segurança, mesmo que esse dom não seja incondicional, no sentido de que aquele que recebe não pode dispor à vontade do que recebeu como o consumidor na troca mercantil (UKPABI e KARJALUOTO, 2017).

Para Fernandes, Altura e Laureano (2018) que define hospitalidade como sendo $o$ ato de acolher e prestar serviços a alguém que por algum motivo esteja fora do seu local de domicílio, a hospitalidade não consiste em dar um espaço ao outro, mas em receber o outro no seu espaço. Fernandes, Altura e Laureano, (2018) melhor exprime a definição anterior, como: o entendimento mais amplo a respeito da hospitalidade sugere, em primeiro lugar, que esta é fundamental, o relacionamento construído entre anfitrião e o hóspede". Camargo, (2015) complementa, dizendo que: ... nada representa a hospitalidade que o ato de acolher pessoas que batem à porta. Buscar o aperfeiçoamento do saber receber seus hóspedes significa a atenção que se dá para eles.

A maneira de como falar e se dirigir ao cliente passa a ter mais importância que o processo de trabalho em si. Ao se considerar que "a hospitalidade deve ser entendida no seu sentido mais amplo de qualificar as relações sociais entre uma comunidade estabelecida e os estrangeiros (ao lugar) que virão visitá-la ou simplesmente descansar" (LOPES e OLIVEIRA, 2013), estão se colocando diante de questões pertinentes ao cotidiano das cidades contemporâneas, de maneira particularmente aguda, implicando assim, numa profunda reflexão sobre elas.

Para qualquer estudo sobre hospitalidade, deve-se levar em conta a afirmação de Lashley (2017, p.10), em que:

... o conceito de hospitalidade estende-se para além dos limites de hotéis, restaurantes, lojas ou estabelecimentos de entretenimento. Isso implica a necessidade de recorrer a análises de caráter histórico, epistemológico e empírico das ações que são empreendidas na área da hospitalidade.

Quando se estuda a hospitalidade, é preciso entender que existe, intrinsecamente, na hospitalidade substantiva, o que Camargo (2015) descreve como fato social que é construído por vários cenários, formando uma escala de abrangência da casa aos países. No modo como o indivíduo se vê, a maneira como o arredor é visto, sentido e/ou percebido são formas únicas de percepção que acabam atuando direta ou indiretamente no processo da projeção que o turista terá sobre o local visitado. A percepção, segundo Kozel e Kashiwagi (2001), associa-se à construção dos mapas cognitivos e é única em cada indivíduo.

A hospitalidade não é somente um fenômeno sociocultural, é um agregado de diversos elementos e, retratar este fenômeno como um produto pronto para ser comercializado é desconsiderar o que não pode ser vendido, apenas trocado: os simbolismos envolvidos na interação humana. 
Conforme Lashley e Morrison (2004, p.5) apresenta:

(...) cada domínio representa um aspecto da oferta da hospitalidade, que é tanto independente como sobreposto. O domínio social da hospitalidade considera os cenários sociais em que a hospitalidade e os atos ligados à condição de hospitalidade ocorrem junto com os impactos de forças sociais sobre a produção e consumo de alimentos, bebidas e acomodação. O domínio privado considera o âmbito das questões associadas à oferta da "trindade" (Oferta de alimentos, bebidas e acomodação) (...)

Desse modo, a hospitalidade torna-se um ato de estreitamento das relações entre pessoas que, conforme Lashley e Morrison (2004) divide-se em três domínios, baseados em cenários onde estas atividades acontecem, sendo em ambientes social, privado e comercial, de acordo com a Figura 1.

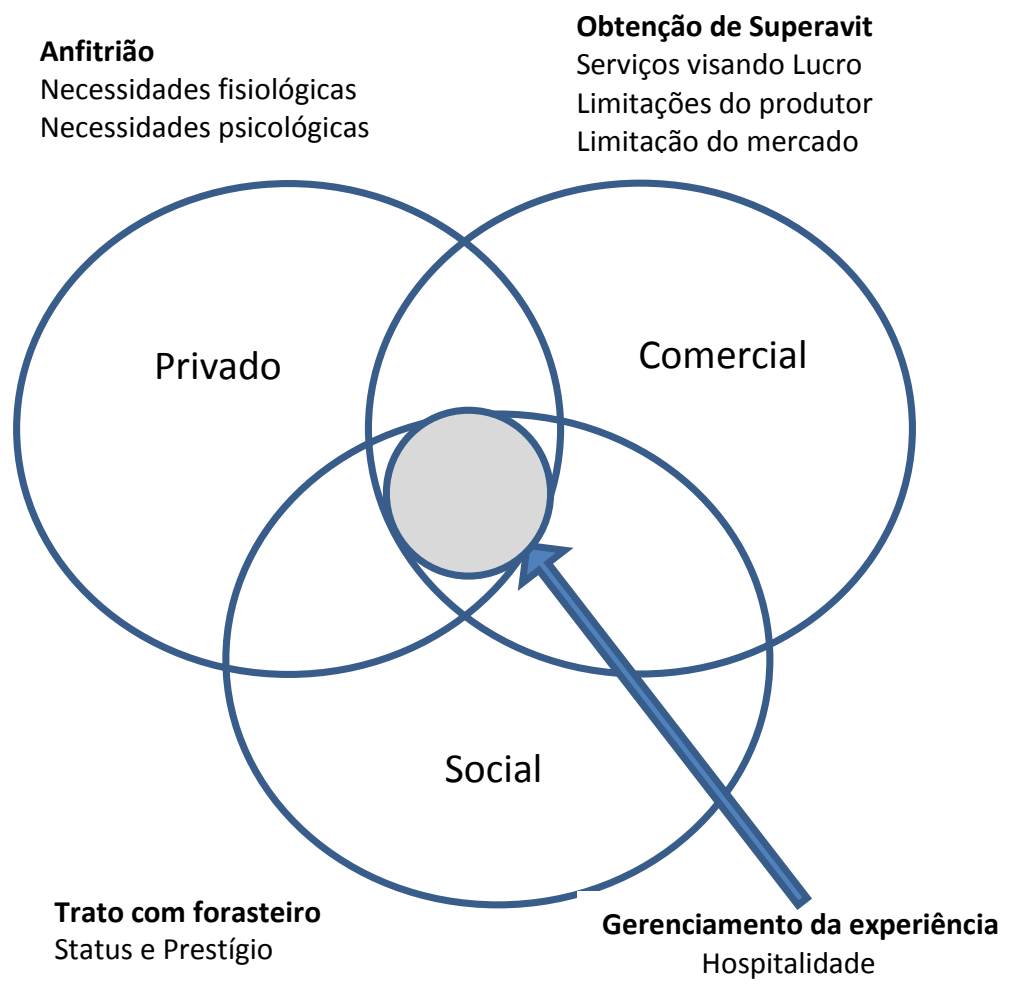

Figura 1: Domínios da hospitalidade

Fonte: Lashley e Morrison, 2004, p. 6

\subsection{Desenvolvimento sustentável}

Dada as novas demandas por produtos ecológicos, organizações dos diferentes segmentos econômicos deverão estabelecer parcerias em projetos conjuntos, ao longo de cadeias produtivas integradas e de serviços sustentáveis (TACHIZAWA, 2019). O desempenho dos órgãos governamentais e empresas também será significativamente influenciado pela pressão das organizações não governamentais - ONG, em direção a um futuro de desenvolvimento sustentável. 
Esse desenvolvimento, de forma interdependente, está relacionado com o crescimento econômico, com a melhoria da qualidade de vida das pessoas e com a conservação do meio ambiente. Como desenvolvimento sustentável, deve ser autossuficiente para suprir as necessidades da população, sem comprometer a capacidade de atender às necessidades das futuras gerações. É o desenvolvimento que não esgota os recursos para o futuro, conforme conceito endossado pela Comissão Mundial sobre Meio Ambiente e Desenvolvimento, criada pelas Nações Unidas para harmonizar o desenvolvimento econômico e a conservação ambiental.

Coerente com este cenário, originou-se o Índice de Desenvolvimento Humano - IDH, definido pelo Programa das Nações Unidas para o Desenvolvimento (PNUD, 2011), com propósito de desafiar as estreitas definições econômicas de progresso que compõem o produto interno bruto (PIB). Ele incorpora, além de indicadores econômicos e sociais, as estatísticas sobre alfabetização, dados sobre a expectativa de vida e poder de compra, tornando-se instrumento de mensuração da condição de vida de países, estados e municípios.

O Brasil ocupa a 79a posição no ranking do IDH $2018(0,759)$, em uma lista que traz 187 países. O Brasil caiu quatro posições em relação ao ano passado de 2014 e tem desenvolvimento humano considerado alto, segundo o relatório do PNUD (2018).

A ideia da construção de indicadores para projetos socioambientais vem ganhando força entre dirigentes e técnicos dos vários tipos de organizações do Terceiro Setor, de financiadores e doadores, assim como junto ao público beneficiado, órgãos governamentais, imprensa e comunidade empresarial. Em grande parte, a motivação para a avaliação mais precisa de resultados e impactos dos projetos, teve origem nas agências doadoras e financiadoras de cooperação internacional.

Além de preocupadas em saber os efeitos e resultados de tantos anos de apoio a organizações do Terceiro Mundo, viram-se pressionadas por seus governos e contribuintes a apresentar os resultados efetivos dessa cooperação não governamental. As perguntas eram e continuam sendo: A ajuda ao Terceiro Mundo está revertendo os quadros de pobreza, miséria, desigualdade social e ausência de direitos básicos? A reação de muitas organizações a essa demanda deu-se como uma crítica à utilização das noções de eficiência e (??) eficácia na mensuração de processos complexos, por expressar uma visão economicista e mecânica(?) da realidade.

Para a Organization for Economic Cooperation and Development (OECD, 2015), um indicador deve ser entendido como um parâmetro, ou valor derivado de um parâmetro, que aponta e fornece informações sobre o estado de um fenômeno com uma extensão significativa. Dessa forma, o uso de indicadores, que se utilizam do conceito de desenvolvimento sustentável, tornou-se uma referência internacional evidenciando, sobretudo, que nem sempre o aumento da riqueza significa melhoria da qualidade de vida da população.

Países com alta renda per capita, portanto, podem apresentar baixos indicadores de desenvolvimento, assim como o inverso também pode ocorrer. Os Indicadores de Desenvolvimento Sustentável, do nosso país com dados dos municípios, envolvendo fatores econômicos, sociais e ambientais estão disponíveis 
em (IBGE, 2010). Porém, dados mais recentes de 2018, podem ser obtidos por estimativas, atualizadas anualmente, pelo próprio IBGE.

O desenvolvimento sustentável é um processo que atende às necessidades do presente sem comprometer a capacidade das gerações futuras de atender suas próprias necessidades. O desenvolvimento sustentável continuou a evoluir como intuito de proteger os recursos do mundo, no entanto, a sua verdadeira agenda é controlar esses recursos. O crescimento econômico ambientalmente sustentável refere-se ao desenvolvimento econômico que atenda às necessidades de todos sem deixar as gerações futuras com menos recursos naturais do que as que desfrutamos hoje.

A essência dessa forma de desenvolvimento é uma relação estável entre as atividades humanas e o mundo natural, o que não diminui as perspectivas de que as gerações futuras desfrutem de uma qualidade de vida pelo menos tão boa quanto a nossa. A ideia de crescimento econômico ambientalmente sustentável não é nova. Muitas culturas ao longo da história humana reconheceram a necessidade de harmonia entre o meio ambiente, a sociedade e a economia. O "crescimento econômico ambientalmente sustentável" é sinônimo do conceito predominante de "Desenvolvimento Sustentável". O objetivo é alcançar equilíbrio e harmonia entre sustentabilidade ambiental, sustentabilidade econômica e sustentabilidade sóciopolítica.

Neste sentido, o Programa de Zoneamento Ecológico-Econômico (BRASIL, 2011) é um instrumento de organização do território a ser observado, tanto na esfera pública quanto na privada. Ele estabelece medidas e padrões de proteção ambiental, destinados a assegurar a qualidade ambiental dos recursos hídricos e do solo e a conservação da biodiversidade, garantindo assim, o desenvolvimento sustentável e a melhoria das condições de vida da população.

Sua importância e seu potencial de planejamento podem ser sinalizados como um instrumento:

- intrínseco na busca pela eficácia e competitividade dos lugares no mundo globalizado, com tentativas de abrandamento da soberania do país, em que potencialidades e limitações naturais se conectam, da organização do território às contingências e potencialidades sociais;

- de estado que possibilita recuperar uma visão de conjunto da nação, bem como subsidiar políticas autônomas para uso estratégico do território;

- que concretiza um novo arranjo institucional do sistema de planejamento, ao funcionar como um processo de avaliação de alternativas, servindo como base de articulação às ações públicas e privadas que participam da reestruturação do território, segundo as necessidades de proteção, recuperação e de desenvolvimento;

- enquadrado na noção contemporânea de política pública, tendo por horizonte a redução da desigualdade social e o respeito ao pluralismo, contribuindo para a prática de uma cidadania participativa à medida que pressupõe a abertura de canais institucionais com a sociedade para fins de consulta e cogestão, articulando enfoques, cada qual como integrador de atores e temas específicos. 
Neste contexto de métricas de desempenho e de qualidade, insere-se 0 conjunto de indicadores de sustentabilidade, ora proposto. De forma complementar e motivado pela existência de uma lacuna entre aquilo que os gestores necessitam em termos de planejamento socioambiental e o que realmente eles dispõem no dia-a-dia da gestão pública, foi desenvolvido o presente trabalho.

Objetivou-se conceber uma base de dados, com uma coleção de registros de sustentabilidade e das relações entre eles, para que governantes e gestores públicos sejam capazes de formular modelos de desenvolvimento local, alicerçados em indicadores socioambientais.

$\mathrm{E}$ tal enfoque torna-se profícuo na esfera governamental, à medida que tais modelos estejam voltados para ordenar a ocupação de espaço dos recursos naturais e de infraestrutura. Este processo, quando voltado ao mapeamento socioambiental, e planejado de forma consistente, permite integrar os interesses de diversos grupos sociais e políticos na definição do futuro de qualquer região (BRASIL, 2011).

\section{Metodologia de pesquisa}

A pesquisa caracteriza-se como exploratória e descritiva. É exploratória, pois sua principal finalidade é a de desenvolver, esclarecer e modificar os conceitos e as ideias para a formulação de abordagens mais condizentes com o desenvolvimento de estudos posteriores. E é descritiva, uma vez que procurou descrever a realidade como ela é sem se preocupar em modificá-la (GIL, 2008, p.15). Observando tais preceitos metodológicos, foi realizado um estudo de caso único, na Prefeitura de Campo Limpo, que passava por significativas mudanças estruturais.

A pergunta-problema estabelecida no desenvolvimento da pesquisa ficou circunscrita a: "Como promover e fomentar o desenvolvimento sustentável do turismo local com a capacitação dos gestores e técnicos através de programa de treinamento apoiado por software livre e o Ensino a distância?" A interatividade, permitida pelo ambiente virtual do software Moodle para alavancar conhecimentos específicos em turismo sustentável e em hospitalidade, foi utilizada.

Inicialmente, foi desenvolvida a coleta de dados primários e secundários. Esses dados primários foram obtidos na pesquisa de campo por meio das entrevistas feitas a gestores e técnicos dos governos municipais, envolvidos no programa de treinamento. Os dados primários obtidos e analisados serviram para evidenciar a vocação econômica do município e da região para o turismo, como alternativa à tradicional industrialização.

Para viabilizar o desenvolvimento regional centrado no turismo sustentável e na hospitalidade, o modelo de gestão pelo qual se optou foi a criação de consórcio de prefeituras locais. Para tanto, foi implementado um programa de capacitação gerencial em turismo sustentável e hospitalidade, que permitisse suporte instrucional ao modelo de gestão municipal, integrado no âmbito da Prefeitura de Campo Limpo Paulista e dos demais governos municipais associados ao consórcio regional (Atibaia, Cabreúva, Itupeva, Jarinu, Louveira, e Várzea Paulista).

O trabalho, sob a ótica de seu objetivo geral, foi conduzido como pesquisa exploratória, através de levantamento bibliográfico, entrevistas com pessoas que tiveram experiências práticas com o problema pesquisado e a análise de exemplos que estimulassem sua compreensão (SELLTIZ et al., 1987, p. 63). Este enfoque 
permitiu analisar os fatos do ponto de vista empírico, para depois confrontar a visão teórica com os dados da realidade. Entrevistas semiestruturadas, observação de processos e análise documental foram os métodos de levantamento de dados adotados nessa formulação. A técnica de entrevista aplicada junto aos gestores municipais justificou-se por ser uma forma de levantamento de posição que conduz os entrevistados a exporem suas percepções a respeito das situações, dos fenômenos e dos problemas associados ao objeto da pesquisa, mediante o diálogo com o entrevistador.

Os entrevistados foram os gestores e técnicos das unidades organizacionais, participantes do curso de capacitação em turismo. Noventa e sete entrevistas semiestruturadas foram aplicadas ao longo do ano de 2015, entre os meses de Janeiro e Novembro e tiveram duração média de duas horas. A análise de dados foi realizada de forma a agrupar os resultados por nível hierárquico na Prefeitura, o que garantiu um alinhamento de percepções por grupos de pessoas com perfis, características e responsabilidades semelhantes.

\section{Discussão dos resultados}

\section{Avaliação do programa de treinamento e resultados}

O município de Campo Limpo Paulista, objeto desse estudo, está inserido na região metropolitana de São Paulo, sendo considerado como uma referência em recursos naturais e reservas ecológicas. Com uma população com mais de setenta mil habitantes, está localizado no sudoeste do Estado de São Paulo, a cerca de 50 quilômetros da Capital e o acesso principal ao município se dá pela Rodovia Anhanguera e pela Rodovia Dom Pedro I. A indústria é o componente econômico, ao lado da agricultura (hortifrutigranjeiros e extrativismo vegetal), que alavancou a emancipação política do município. Este surto desenvolvimentista, baseado na atividade industrial, provocou uma saturação econômica, criando uma demanda reprimida por atividades de prestação de serviços, entre elas, o turismo, conforme enfocado neste estudo. A prefeitura do município de Campo Limpo apoiou-se também no Índice de Desenvolvimento Humano - IDH (PNUD, 2011), que parte do pressuposto de que para aferir a evolução de uma comunidade não se deve considerar apenas a dimensão econômica, mas também outras características sociais, culturais e políticas que influenciam a qualidade da vida humana.

Os dados da cidade estão coerentes com o Programa de Pesquisas em Caracterização, Conservação e Uso Sustentável da Biodiversidade do Estado de São Paulo, denominado BIOTA-FAPESP (2010) que considera a região administrada pela Prefeitura, como uma área prioritária para a implementação de novas estratégias para conservação e recuperação da biodiversidade nativa do Brasil. Visando à melhora do IDH do município de Campo Limpo, a implementação das atividades turísticas ora propostas pela Prefeitura poderá vir a atenuar a carência significativa de emprego e renda. Na Tabela 1, abaixo são apresentados os dados do SEADE (2016) sobre o Município de Campo Limpo Paulista. 
Tabela 1. Dados socioeconômicos do Município de Campo Limpo Paulista

\begin{tabular}{|l|r|r|r|r|}
\hline \multicolumn{1}{|c|}{ DADOS } & Ano & Município & \multicolumn{1}{c|}{ Região } & \multicolumn{1}{c|}{ Estado } \\
\hline Área (Km2) & 2015 & 79,4 & $1.738,49$ & $248.219,63$ \\
\hline População & 2016 & 81.979 & 917.281 & 44.314 .930 \\
\hline Densidade Demográfica. (habitantes / Km2) & 2016 & 1.032 & 528 & 178,53 \\
\hline Grau de Urbanização. (em \%) & 2016 & 100 & 95,26 & 96,47 \\
\hline Índice de envelhecimento (em \%) & 2017 & 65,74 & 75,16 & 78,134 \\
\hline População < 15 anos. (em \%) & 2017 & 20,05 & 18,95 & 19,02 \\
\hline População > 60 anos. (em \%) & 2017 & 13,18 & 14,24 & 14,86 \\
\hline Taxa de natalidade por 1.000 habitantes & 2017 & 13,19 & 14,51 & 14 \\
\hline Taxa de mortalidade infantil (por 1.000 nascidos) & 2017 & 11,33 & 11,92 & 10,74 \\
\hline IDHM & 2010 & 0,769 & 0,771 & 0,783 \\
\hline Renda per capita (em Reais) & 2010 & 677,02 & 894,46 & 853,75 \\
\hline Coleta de lixo (em \%) & 2015 & 99,64 & 99,82 & 99,66 \\
\hline Abastecimento de água (em \%) & 2015 & 92,06 & 94,75 & 97,91 \\
\hline Esgoto sanitário (em \%) & 2015 & 65,11 & 88,82 & 89,75 \\
\hline Taxa analfabetismo população < 15 anos & 2010 & 4,22 & 3,97 & 4,33 \\
\hline Ensino médio completo entre 18 a 24 anos (em \%) & 2015 & 65,77 & 58,4 & 57,89 \\
\hline Renda média de funcionários na Indústria (em Reais) & 2016 & $4.502,44$ & $4.036,74$ & $3.796,28$ \\
\hline Renda média na Pecuária e Agricultura (em Reais) & 2016 & $1.549,24$ & $1.659,69$ & $2.006,99$ \\
\hline Renda média na construção civil (em Reais) & 2016 & $1.832,11$ & $2.624,88$ & $2.719,49$ \\
\hline Renda média de Serviços e Comercio (em Reais) & 2016 & $2.658,23$ & $2.941,56$ & $3.057,50$ \\
\hline Renda média Total de funcionários (em Reais) & 2016 & $3.216,42$ & $3.170,21$ & $3.287,67$ \\
\hline PIB (em milhões de Reais) & 2016 & $1.676,00$ & $1.407,23$ & $2.038,01$ \\
\hline PIB per capita (em Reais) & 2016 & $21.096,02$ & $80.655,33$ & $47.003,04$ \\
\hline Participação do PIB no Estado (em \%) & 2016 & 0,08237 & 3,50378 & 100,00 \\
\hline
\end{tabular}

Fonte: Dados obtidos Fundação SEADE (2016)

As condições de vida, no município, conforme evidenciam dados discriminados na Tabela 1 têm, ainda, muito a evoluir, daí a razão da opção da Prefeitura pela proposta de desenvolvimento do turismo sustentável na região. Os dados primários (pesquisa de campo e entrevistas) e secundários obtidos com a prefeitura local, foram base para estabelecer o modelo de gestão de turismo municipal. Este modelo, constituiu o conteúdo principal do curso de capacitação em turismo com uso do software livre Moodle.

\subsection{Modelo de gestão utilizado no programa de treinamento}

A Prefeitura de Campo Limpo vivenciava um processo de mudança organizacional em direção a um modelo de gestão que visasse proporcionar maior autonomia decisória aos seus gestores das unidades turísticas e de apoio 
administrativo, o que permitiria a tomada de ações estratégicas em turismo, de forma ágil e descentralizada.

O modelo de gestão do turismo municipal contemplava todos os aspectos relacionados aos processos turísticos e de apoio a turistas, colaboradores, munícipes, fornecedores de serviços, pessoal terceirizado e comunidade. Considera, ainda, a existência da dimensão vertical da estrutura organizacional da Prefeitura, que leva em conta os três departamentos que, funcionalmente, cuidam das atividades turísticas: turismo receptivo; turismo social e turismo ecológico. Nesta dimensão funcional, espelhada pelo organograma deste Governo Municipal, ficou evidenciada a necessidade de apoio de todas suas unidades municipais aos três departamentos de turismo, uma vez que a cadeia turística implementada perpassa, horizontalmente, as unidades da estrutura organizacional da Prefeitura.

Essas decisões apoiam-se nos pressupostos da sustentabilidade ecológica e da hospitalidade. Esta última, enfatizando o processo de receber e atender os turistas com a cultura e os valores da comunidade e assim, manter e reforçar a identidade comunitária. A sustentabilidade econômica, por outro lado, se compatibilizava com a preservação do processo ecológico, essencial à diversidade biológica e aos recursos naturais. Essa cadeia sistêmica, que foi a base do conteúdo programático do curso virtual em turismo, envolveu atividades ligadas à opção adotada de sustentabilidade do turismo e de hospitalidade no município (premissa estabelecida pelos Gestores da Prefeitura), em termos de:

a) realizar estudos tendentes a explicar os fenômenos turísticos locais;

b) analisar os efeitos dos polos emissores e receptores sobre os indivíduos, grupos ou categorias sociais e inferências sobre práticas e hábitos dos fluxos turísticos;

c) elaborar projetos e estudos de planejamento, organização, funcionamento e exploração de empreendimentos turísticos em parceria com organizações privadas e públicas;

d) otimizar e equilibrar os benefícios econômicos, ambientais e sociais do turismo, com distribuição para a comunidade local;

e) estabelecer diretrizes e padrões para desenvolvimento do turismo, da sustentabilidade e da hospitalidade.

$\mathrm{Na}$ condução da pesquisa, procurou-se confirmar a provável sinergia entre desenvolvimento econômico, conservação ambiental e hospitalidade e abrangeu-se o conjunto de serviços diferenciados turisticamente, que o município teria a oferecer aos visitantes da região. Foi dada ênfase especial àqueles bens e serviços turísticos que possibilitariam o exercício do ecoturismo e atividades autossustentáveis, com potencial de criação de empregos e renda à comunidade local.

\subsection{Implementação do programa de ensino virtual em turismo}

Os requisitos demandados pela implementação do Moodle no Curso de Capacitação em Turismo para os gestores e técnicos municipais evidenciaram a necessidade de se adotar um enfoque sistêmico na inserção dessa nova tecnologia na Prefeitura. Esta abordagem permitiu que fosse analisado, previamente, o 
contexto estratégico turístico do Município para, posteriormente, implementar o Curso de Turismo no ambiente virtual. Outra constatação percebida pela implementação do Moodle foi a necessidade de comprometimento dos que ocupam a alta direção da Prefeitura com o curso implementado, e da disponibilidade de investimentos em infraestrutura tecnológica.

Foi exatamente em face de tal definição que foi tomada a decisão tecnológica nos contornos delineados pelo modelo de aprendizagem, considerando alternativas como a terceirização total, com a contratação de uma empresa especializada ou a contratação parcial de terceiros, ou ainda, inteiramente assumida pela própria Prefeitura.

E, no contexto deste modelo foi utilizado o software Moodle, fundamentado nas necessidades de demanda de sua cadeia turística municipal. O Curso de Turismo foi estruturado, conforme salientam Ansarah (2009) e Bissoli, (2001) dentro do ambiente virtual Moodle, em quatro fases, todas, articuladas e integradas de forma coesa, em um único curso de capacitação gerencial em turismo sustentável e hospitalidade.

A primeira fase abrangeu disciplinas relacionadas ao contexto institucional, tais como: planejamento turístico; plano diretor para o governo municipal; planejamento e controle estratégico e pressupostos de planejamento turístico. $\mathrm{Na}$ segunda fase, contemplou-se o treinamento específico, relacionado ao modelo de gestão do turismo municipal adotado em relação aos aspectos relacionados aos processos turísticos e de apoio a turistas, colaboradores, munícipes, fornecedores de serviços, pessoal terceirizado e comunidade. Na terceira fase, foram abordadas disciplinas específicas de gestão socioambiental (TACHIZAWA, 2019), em termos de: desenvolvimento sustentável; cadeia turística municipal; hospitalidade; turismo receptivo; turismo social; e turismo ecológico. Como quarta fase, definiu-se o desenvolvimento, ao longo do curso, de um projeto real, em que todos os conceitos ministrados em sala de treinamento, presencial e virtual, fossem abordados no contexto profissional de cada participante do Curso de Turismo.

\subsection{Treinamento no ambiente virtual Moodle}

Para a escolha do ambiente de ensino virtual, foram analisadas outras opções disponíveis (além de outros programas aplicativos existentes no mercado), dentre elas, produtos comerciais como WebCT, Lotus Learning Space e Blackboard eEducation, bem como projetos acadêmicos não comerciais (AulaNet e Virtual-U); além daqueles considerados experimentais. Foi escolhido o software Moodle, dada a sua facilidade de criação de ambientes educacionais (interatividade, estrutura e ferramentas) baseados na Internet.

Sua arquitetura de e-learning adotou sessões educacionais com aplicações interativas de multimídia, na forma de: a) salas de aulas virtuais; b) chat para discussão de assuntos entre treinados e, entre esses, o instrutor; c) mural para afixação de avisos virtuais; d) e-mail na forma tradicional para formalizar a comunicação entre instrutor, treinados e apoio acadêmico.

O programa-aplicativo Moodle (Modular Object-Oriented Dynamic Learning Environment), como um software livre de apoio à aprendizagem é classificado como RELUNA, Belo Horizonte - MG, Brasil, v.23, n.4, p.42-61, Dut. - Dez. 2018 - ISSN 2179-8834 
um ambiente virtual de aprendizagem. É, também, classificado como um sistema de gestão de cursos. Na sua implementação, direcionada ao curso de capacitação em turismo, deparou-se com a necessidade de tomar decisões em relação à configuração de sua estrutura de aprendizagem, que poderia ser adotada em termos de: formato semanal; formato em tópicos e formato social. No caso, adotou-se o formato em tópicos, em que cada tema do curso de capacitação em turismo constitui um grupamento único de aulas ministradas de forma modular.

$\mathrm{Na}$ criação do ambiente virtual do Curso de Capacitação Gerencial em Turismo, efetuou-se um criterioso planejamento visando a identificar as tecnologias de suporte a serem adotadas e como oferecê-las. Utilizou-se duas seções, assim como a opção de atendimento, o que tornou o trabalho até mais fácil, com o instrutor utilizando ideias levantadas em uma seção, ao fazer comentários na discussão da outra seção do curso e, dessa forma, proporcionou um importante benefício adicional, que o ensino online traz ao instrutor. As ideias geradas em discussões online são simplesmente melhores e mais instigantes que as geradas na sala de aula tradicional.

Dessa forma, a distância entre educação e entretenimento, vai sendo atenuada por meio de uma educação virtual cada vez mais presente nos dias de hoje. A sala de aula virtual é uma experiência para ser implantada em doses pequenas. Considerando que os alunos preferem respostas rápidas às suas indagações e o instrutor deve estar preparado para trabalhar de forma síncrona. $\mathrm{Na}$ realidade, a preferência dos alunos de trabalharem de forma síncrona, espelha o aspecto cultural presente na sociedade, onde existe a propensão natural de não entender a liberdade que o ambiente de ensino virtual proporciona. Estas características foram observadas na implementação do curso virtual em Turismo sustentável e hospitalidade.

O Curso de Capacitação em Turismo Sustentável e Hospitalidade foi configurado, dando ênfase para as datas de encerramento de inscrições, em que foi possível atualizar, sistematicamente, a categoria do curso. Neste mesmo recurso sistêmico tem-se várias configurações, tais como a alteração da data de início do curso e o tamanho máximo de upload (tamanho máximo de arquivos a serem postados no ambiente) e que podem ser configurados com as opções oferecidas pelo Moodle.

No Curso de Capacitação em Turismo, além de tecnologias da informação, que constituíam o arcabouço da infraestrutura de hardware e software, procurou-se contemplar a preparação do conteúdo didático-pedagógico e o formato do curso, que foram os pontos críticos do programa de Ensino à distância. Complementarmente ao aspecto tecnológico, o suporte técnico e pedagógico (liderado pelo professor/instrutor) aos treinados do curso em turismo que objetivou manter a motivação da classe virtual.

Insere-se neste contexto o suporte técnico, uma vez que as dificuldades e problemas (versões de programas, configuração de equipamentos, conexões com o provedor de acesso instáveis e afins) que surgem no âmbito da infraestrutura de hardware e software podem comprometer o ambiente virtual do processo ensinoaprendizagem. As aulas online em Turismo procuraram compatibilizar recursos da infraestrutura tecnológica em termos de hardware e software e enfoque sistêmico no 
processo ensino-aprendizagem, uma vez que os elementos do referido ambiente sofrem significativas alterações. $m$

$\mathrm{Na}$ escolha do ambiente de ensino virtual, foram analisadas outras opções disponíveis (além de outros programas aplicativos existentes no mercado), dentre elas, produtos comerciais como WebCT, Lotus Learning Space e Blackboard eEducation; bem como projetos acadêmicos não comerciais (AulaNet e Virtual-U); além daqueles considerados experimentais. Foi escolhido o software Moodle dada a facilidade de criação de ambientes educacionais (interatividade, estrutura e ferramentas) baseados na Internet.

\subsection{Principais resultados}

Neste ambiente virtual de aprendizagem 0 papel do instrutor foi preponderante, uma vez que o Moodle exigia quatro funções nas quais um usuário poderia ser inscrito no curso: tutor; moderador; estudante (treinando); e visitante (convidado). Essa funcionalidade poderia ser usada para que o instrutor designasse um monitor para a sua disciplina.

Fator importante para o sucesso do programa é o estágio de informatização em que se encontrava a Prefeitura, o que deve ser levado em conta na implementação do ambiente virtual de aprendizagem. Dessa maneira, uma Prefeitura já amplamente informatizada leva vantagem sobre outros municípios que não estejam em estágio de informatização avançado. No caso deste estudo, foi necessário fazer adequações dos sistemas para a plena implantação do Curso.

Sua arquitetura de e-learning adotou sessões educacionais com aplicações interativas multimídia, na forma de:

a) salas de aulas virtuais;

b) chat para discussão de assuntos entre treinados, e entre estes e o instrutor;

c) mural para afixação de avisos virtuais;

d) e-mail na forma tradicional para formalizar a comunicação entre instrutores treinados e apoio acadêmico.

Foi estruturado, também, um banco de conhecimentos para armazenamento do conteúdo do curso (disciplinas e programas de treinamento); dados de treinados e instrutores; material didático (apostilas); informações do quadro de avisos virtual (mural); e demais informações educacionais. Neste ambiente de ensinoaprendizagem virtual o treinando poderia assistir aulas de forma presencial e virtual.

A implementação do software Moodle, na forma de um curso virtual de capacitação em turismo sustentável, para fins de utilização de novas técnicas e de conceitos na cadeia turística municipal integrada, coerente com o modelo de gestão e de crenças e valores dos governos municipais, abrangidos pelo estudo, apresentou resultados condizentes com os pressupostos iniciais.

Em 2016, a ação proporcionou os seguintes resultados: aumento médio de $11,9 \%$ no movimento do turismo na região, redução aos danos ao meio ambiente, melhor modo de recepcionar o visitante, conforme tabela 2, abaixo. 
Tabela 2. Ganhos com a implantação do treinamento

\begin{tabular}{|c|c|c|c|c|c|c|c|}
\hline DADOS EM \% & $\begin{array}{c}\text { Campo } \\
\text { Limpo } \\
\text { Paulista }\end{array}$ & Atibaia & Cabreuva & Itupeva & Jarinu & Louveira & $\begin{array}{c}\text { Várzea } \\
\text { Paulista }\end{array}$ \\
\hline Aumento do Turismo * & 14,5 & 18,0 & 9,5 & 10,0 & 11,0 & 13,0 & 7,0 \\
\hline $\begin{array}{c}\text { Redução de danos } \\
\text { ao ambiente. ** }\end{array}$ & 16,0 & 11,0 & 6,0 & 10,0 & 13,5 & 12,0 & 8,0 \\
\hline Satisfação do visitante * & 73,0 & 71,0 & 60,0 & 45,0 & 68,0 & 55,0 & 30,0 \\
\hline Aumento de receita * & 13,0 & 20,0 & 16,5 & 13,5 & 17,0 & 21,0 & 9,0 \\
\hline $\begin{array}{c}\text { Geração de emprego } \\
\text { em turismo. * }\end{array}$ & 22,0 & 15,5 & 9,5 & 11,0 & 15,5 & 18,5 & 8,0 \\
\hline
\end{tabular}

* Dados de 2016 comparados com dados de 2014

** Dados de 2016 comparados com dados de 2012

Fonte. Dados das Prefeituras da região (2016)

\section{Considerações finais}

O objeto do estudo foi a avaliação de um programa de treinamento virtual em turismo sustentável, que permitisse suporte instrucional em capacitação gerencial ao modelo de gestão municipal integrado no âmbito da Prefeitura de Campo Limpo Paulista e dos demais governos municipais associados do consórcio regional.

Baseado na filosofia sócio construtivista, o Moodle ofereceu diversos recursos que facilitaram a abordagem colaborativa e a construção coletiva do conhecimento em Turismo. O programa de treinamento em turismo sustentável e hospitalidade permitiu a criação de um ambiente virtual, com ênfase no trabalho em grupo entre seus participantes e instrutores, como complemento ao ensino semipresencial do referido curso.

O modelo permitiu que os gestores das unidades diretamente vinculadas às atividades de turismo, bem como dos coordenadores dos demais segmentos organizacionais dos governos municipais, que apoiam as atividades-fim (cadeia turística municipal), recebessem capacitação em turismo sustentável e em hospitalidade.

Os resultados da implementação deste projeto de ensino-aprendizagem em turismo, viabilizaram em valores médios: a preservação da sustentabilidade ao longo de toda cadeia turística da Prefeitura Municipal de Campo Limpo Paulista e dos demais associados do consórcio regional (redução de 11,5\%), como também, a melhora dos procedimentos de receber, atender e agradar os visitantes (incremento do turismo $18,0 \%$ ) e incremento de empregos (15,0\%).

Como limitações da pesquisa tem-se o fato de ela ter sido realizada em uma região que corresponde a tão somente $2,0 \%$ da população e de $3,5 \%$ do PIB do Estado de São Paulo, portanto não ampla em sua abrangência.

Recomenda-se que estudos similares e específicos sejam realizados e desenvolvidos, também, para explorar os recursos do processo ensinoaprendizagem, aplicáveis a programas de capacitação gerencial em Turismo, de interesse específico em outras regiões. 


\section{Referências}

ANSARAH, M. G. R. Turismo 2: como aprender como ensinar. São Paulo: Senac. 2009.

AARSTAD, J., KVITASTEIN, O. A. and JAKOBSEN, S. Related and unrelated variety in a tourism context. Annals of Tourism Research. vol. 57, p.234-278. 2016.

BARMA, N. H., DURBIN, B., LORBER, E. and WHITLARK, R. E. Imagine a World in Which: Using Scenarios in Political Science. International Studies Perspectives. vol.17, p.117-135. 2016.

BISSOLI, M. A. M. A. Planejamento turístico municipal com suporte em sistemas de informação. São Paulo: Futura. 2001.

BRASIL, Ministério do Meio Ambiente. "Programa Zoneamento EcológicoEconômico". PROBIO - Projeto de Conservação e Utilização Sustentável da Diversidade Biológica Brasileira. Brasília: 2011.

BRIA, F. Ours to Hack and to Own. The rise of platform cooperativism, a new vision for the future of work and a fairer internet. New York, OR Book. 2016'

CAMARGO, L. O. The interstices of hospitality. Research in Hospitality

Management vol. 5, n. 1, p.19-27. 2015.

CARAM, N. R. e BIZELLI, J. L. Aspectos da regulação sobre o ensino a distância no Brasil. UNESP, 2014

DAVID L. JONES, D. L., DAY, J. and QUADRI-FELITTI, D. Emerging Definitions of Boutique and Lifestyle Hotels: A Delphi Study. Journal of Travel \& Tourism Marketing. vol. 30, n.7, p.715-731. 2013.

EMBRATUR. Instituto Brasileiro de Turismo. Estatísticas sobre o Turismo no Brasil. 2018. Disponível em http://www.dadosefatos.turismo.gov.br/2016-02-04-1153-05.html. Acesso em 9 de março, 2019.

FAPESP - Fundação de Amparo a Pesquisa do Estado de São Paulo. Programa de Pesquisas em Caracterização, Conservação e Uso Sustentável da Biodiversidade do Estado de São Paulo. BIOTA-FAPESP. 2010. Disponível em: http://www.biota.org.br. Acesso em 10 de novembro de 2015.

FREE SOFTWARE FOUNDATION. The Free Software Definition. 2009. Disponível em: https://www.fsf.org/. Acesso em: 10 de fevereiro 2018.

FUNDAÇÃO SEADE. Índice Paulista de Responsabilidade Social. São Paulo: Assembleia Legislativa de São Paulo. 2017. Disponível em: http:// www.seade.gov.br. Acesso em: 8 de março de 2019. 
GIL, A. C. Métodos e técnicas de pesquisa social. São Paulo: Atlas. 2008.

LOPES, A. S. e OLIVEIRA N. Hospitalidade e trocas contemporâneas na hotelaria um estudo de caso do quality suítes vila olímpia. TURyDES. vol 6, n.1. 2013

GÖSSLING, S., and LANE, B. Rural tourism and the development of Internet-based accommodation booking platforms: a study in the advantages, dangers and implications of innovation. Journal of Sustainable Tourism, vol.1 n.18. 2014.

HARTE, R., GLYNN, L., RODRÍGUEZ-MOLINERO, A. BAKER, P. M. A., SCHARF, T., QUINLAN, L. R. and ÓLAIGHIN, G. Human-centered design methodology to enhance the usability, human factors, and user experience of connected health systems: a three-phase methodology. Journal JAMIR Human Factors. vol.4.Issue 1. 2017.

IBGE - Instituto Brasileiro de Geografia e Estatística. "Censo Demográfico 2010". Disponível em www.ibge.gov.br. Acesso em 6 de março de 2019.

LASHLEY; MORRISON (Org.). Em busca da hospitalidade: perspectivas para um mundo globalizado. São Paulo: Manole. 2004.

FERNANDES, A., ALTURA, B. e LAUREANO. Validation of the Hospitality Culture Scale in the context of hotel. Tourism \& Management Studies, vol.14, SI. 1, p.4352. 2018.

LEE, B. C. (2013). Impact of social capital on tourism technology adoption for destination marketing. Current Issues in Tourism, vol.1, n.18. 2013.

LOVATEL, R. M. Desenvolvimento de software compartilhado para uso da Administração Pública Federal. Trabalho de grau de especialista em Gestão Pública. ENAP. 2016. Acesso em 12 de novembro 2018.

MOODLE. Modular Object-Oriented Dynamic Learning Environment. Página oficial da ferramenta. Disponível em: http://www.moodlebrasil.net/. Acesso em 25 de novembro de 2015

OECD. Diretrizes da Organização para a Cooperação e Desenvolvimento Econômico para Multinacionais da Organização das Nações Unidas (ONU). Nova York, 2015.

PNUD - Programa das Nações Unidas para o Desenvolvimento. Atlas do desenvolvimento humano no Brasil. Tabela do ranking dos Municípios 2010-2018. Disponível em http://www.pnud.org.br/IDHM, acesso em 9 de março de 2019.

SACHS, I. Rumo à ecossocioeconomia - teoria e prática do desenvolvimento. São Paulo: Cortez Editora. 2007.

SCHUMPETER, J. A. Capitalismo, socialismo e democracia. São Paulo: Editora UNESP. 2017. 
SEADE. Portal do Sistema Estaduais de Análise de dados.2016. Acesso em 11 de março de 2019.

SELLTIZ, C. et al. Métodos de pesquisa nas relações sociais. São Paulo: Herder.1987.

SHIBAYAMA, S. Sustainable development of science and scientists: Academic training in life science labs. Research Policies. vol.48, Issue 3, pp. 676-692. 2018.

SONG, H. LI, G. and CAO, Z. Tourism and Economic Globalization: An Emerging Research Agenda. Journal of Travel Research. vol. 57, issue: 8, p. 999-1011

STALLMAN, R. Free software, free society: selected essays of Richard M. Stallman. Free Software Fundation. Boston. 2010.

TACHIZAWA, T. Gestão Ambiental e Responsabilidade Social Corporativa. São Paulo: Atlas. 2019.

UKPABI, D.C., and KARJALUOTO, H. Consumers' acceptance of information and communications technology in tourism: A review, Telematics and Informatics, vol. 34, no. 5, pp. $618-644.2017$.

YIN, R. K. Estudo de caso: planejamento e métodos. Porto Alegre: Bookman. 2001. 